\title{
ESQUECIMENTO DIGITAL NOS TRIBUNAIS BRASILEIROS: O DIREITO AO ESQUECIMENTO NOS ACÓRDÃOS NO SUPERIOR TRIBUNAL DE JUSTIÇA
}

\author{
DIGITAL OBLIVION IN BRAZILIAN COURTS: THE RIGHT \\ TO BE FORGOTTEN ACCORDING TO THE JUDGMENTS \\ OF THE SUPERIOR COURT OF JUSTICE
}

Frederico Cordeiro Martins ${ }^{a}$

Priscila Reis dos Santos ${ }^{b}$

Rodrigo Moreno Marquesc

\begin{abstract}
RESUMO
Introdução: A aplicação do direito ao esquecimento no contexto digital pelos tribunais brasileiros tem se mostrado como um controverso tema inserido no rol das políticas de informação, especialmente quando se tornam mais frequentes, variadas e fáceis, as formas de divulgação de informações sobre as pessoas e os fatos que as envolvem, criando uma tênue linha entre a privacidade e a liberdade de expressão. Objetivo: Analisar os pronunciamentos dos tribunais brasileiros no que tange a aplicação do direito ao esquecimento no contexto digital. Metodologia: Para consecução deste intento, realizou-se uma pesquisa baseada em levantamentos bibliográfico e documental, cujo percurso metodológico é apresentado na terceira seção deste artigo. Antes dela, o direito ao esquecimento na internet é o assunto abordado na segunda seção do texto. A seguir, apresenta-se uma síntese decorrente do exame dos acórdãos selecionados para o estudo e, ao final, as considerações finais sobre o tema em debate. Resultados: Dentre os resultados alcançados, comprova-se que, além do direito de serem esquecidas, as partes que intentaram as ações pretendiam ser indenizadas em aspectos patrimoniais. Notou-se, ainda, que um tema recorrente nos casos estudados é o limite entre o direito ao esquecimento e à informação. Conclusões: Depreendeu-se, dado o baixo índice de acolhimento das ações dentre os acórdãos analisados, que nem todos os pedidos encontram provimento na justiça brasileira. Concluiu-se, também, que os textos legais e doutrinas não têm sido

a Doutorando em Sistemas de Informação e Gestão do Conhecimento pela Universidade Fumec. Professor na Universidade do Estado de Minas Gerais. E-mail: frederico.cordeiro.martins@gmail.com

b Doutoranda em Sistemas de Informação e Gestão do Conhecimento pela Universidade Fumec. Mestre em Administração. Especialista em Arquitetura e Organização da Informação. E-mail: priscila@fumec.br

c Doutor em Ciência da Informação pela Escola de Ciência da Informação (ECI) da Universidade Federal de Minas Gerais (UFMG). Professor do Departamento de Teoria e Gestão da Informação, na ECI (UFMG).E-mail: rodrigomorenomarques@ufmg.br
\end{abstract}

Inf. Inf., Londrina, v. 26, n. 1, p. 74 - 93, jan./mar. 2021.

http://www.uel.br/revistas/informacao/ 
suficientes para embasarem as decisões dos tribunais, pois autores antes ausentes nos acórdãos garantem, atualmente, até mesmo cocitações nas sentenças.

Descritores: Direito ao esquecimento. Esquecimento digital. Superior Tribunal de Justiça. Política de informação.

\section{INTRODUÇÃO}

O direito à privacidade da informação pessoal e o direito ao acesso à informação pública podem ser considerados garantias fundamentais dos cidadãos nas sociedades democráticas modernas. Bem mais controverso, 0 chamado direito ao esquecimento tem suscitado diversas discussões na proporção que as tecnologias avançam, o volume de dados se avulta e o armazenamento desses se dispersa.

Com o advento da internet, se tornam mais frequentes, variadas e fáceis as formas de divulgação de informações sobre as pessoas e os fatos que as envolvem, o que indica uma maior necessidade de enfrentamento, por exemplo, dos limites entre a privacidade e a liberdade de expressão.

O direito ao esquecimento, foco principal deste trabalho, tem relação direta com os princípios da dignidade da pessoa humana. Esse direito garante ao indivíduo que aspectos de sua vida, caso possuam potencial de causar sofrimento ou transtornos a ele, não sejam divulgados publicamente. Todavia, o banimento e a desindexação de tais informações demandam um processo decisório judicial e análise de várias outras garantias sociais que, conforme 0 caso, podem ser tomadas como concorrentes.

Nesse contexto, o presente trabalho objetiva analisar os pronunciamentos dos tribunais brasileiros no que tange a aplicação do direito ao esquecimento no contexto digital.

Para consecução deste intento, realizou-se uma pesquisa baseada em levantamentos bibliográfico e documental, cujo percurso metodológico é apresentado na terceira seção deste artigo. Antes dela, o direito ao esquecimento na internet é o assunto abordado na segunda seção do texto. A seguir, apresenta-se uma síntese decorrente do exame dos acórdãos selecionados para o estudo e, ao final, encontram-se as considerações finais 
sobre o tema em debate.

\section{DIREITO AO ESQUECIMENTO NA INTERNET}

O direito ao esquecimento está inserido no amplo conceito de política de informação, segundo o qual leis e regulamentos que lidam com a informação, em qualquer um dos estágios da cadeia de produção da informação, constituem políticas de informação (BRAMAN, 2006).

O direito ao esquecimento não é um tema sobre a qual há um consenso quanto ao surgimento de seus fundamentos. Alguns textos o creditam a fatos ocorridos na França ou a uma publicação, editada em 1980, nos Estados Unidos da América. Entretanto, autores como Lima (2013), Cormelato (2014), Ehrahardt Júnior, Nunes, Porto (2017) e Santos (2018) asseguram que o precedente, no mundo, refere-se a um julgamento, na Alemanha, ocorrido no ano de 1973. No caso germânico, o reclamante pleiteava ser olvido da transmissão de um documentário, produzido por um canal de TV, a respeito de um crime, cometido em 1969, cuja condenação havia sido cumprida.

No Brasil, em 2013, durante a VI Jornada de Direito Civil do Centro de Estudos Judiciários do Conselho de Justiça Federal ${ }^{1}$, houve a aprovação do Enunciado 531, o qual expressa que a "dignidade da pessoa humana na sociedade da informação inclui o direito ao esquecimento. Percebe-se, portanto, que para além da questão legal, o direito ao esquecimento deve ser avaliado sob a ótica republicana da dignidade da pessoa humana. Neste sentido, Alves e Gofas (2017) apontam-no como um direito protetivo ou um novo direito originário da sociedade informacional. Esclarecem os autores que o "direito de ser deixado em paz" visa proteger um bem jurídico específico e, por conseguinte, possibilita que referências ao passado de um indivíduo, inúteis para a sociedade, possam ter 0 acesso limitado na rede mundial de computadores (ALVES; GOFAS, 2017).

O paradigma central dos argumentos sobre os pedidos de esquecimento

\footnotetext{
${ }^{1}$ CENTRO DE ESTUDOS JUDICIÁRIOS. Conselho da Justiça Federal. Consulta a enunciados. Disponível em: https://www.cjf.jus.br/enunciados/. Acesso em: 18 ago. 2019.
} 
é, conforme Rodrigues e Oliveira (2015) e Ehrhardt Júnior, Nunes e Porto (2017), o emblemático caso M. C. G. versus La Vanguardia Ediciones SL, Google Spain e Google Inc. Neste processo judicial, iniciado em 2010, foi apresentada, perante a Autoridade Espanhola de Proteção de Dados Pessoais, uma petição solicitando que a editora retirasse ou alterasse páginas que expunham o anúncio de um leilão imobiliário organizado após processo de penhora para a quitação de dívidas previdenciárias do Sr. M. C. G. O requerente, à época, pleiteava ocultação de seus dados pessoais ou que se utilizassem ferramentas específicas para protegê-los nos mecanismos de busca. A reivindicação foi julgada improcedente, mas posteriormente o Tribunal de Justiça Europeu, no ano de 2014, reformou a decisão e assegurou ao autor o direito de exigir a restrição dos resultados das pesquisas feitas no Google. Assim, foram desindexadas páginas do jornal da La Vanguardia, publicadas em 1998, nas quais figurava um anúncio da venda de imóveis, em leilão público, decorrente da execução fiscal de dívidas do requerente Sr. G. junto à Segurança Social.

Ironicamente, por ter logrado êxito no controle de remissões às informações particulares, o Sr. M. C. G. obteve, ainda que involuntariamente, a consagração do seu caso como paradigmático do the right to be forgetten. Assim, tem-se o inusitado quadro de alguém que buscava ser esquecido, mas tornou-se notoriamente indelével na história dos direitos na era digital e, decerto, não voltará ao limbo pelo tempo que houver textos indexados, sobre a temática, em uma das incontáveis bases, publicações ou domínios mundo afora.

Nota-se que o sistema jurídico do Brasil apresenta especificidades em relação ao europeu. A influência do Marco Civil da Internet (Lei № 12.965/2014), conforme consta no Art. $7^{\circ}$, é uma delas:

O acesso à internet é essencial ao exercício da cidadania, e ao usuário são assegurados os seguintes direitos: I inviolabilidade da intimidade e da vida privada, sua proteção e indenização pelo dano material ou moral decorrente de sua violação; [...] X - exclusão definitiva dos dados pessoais que tiver fornecido a determinada aplicação de internet, a seu requerimento, ao término da relação entre as partes, ressalvadas as hipóteses de guarda obrigatória de registros previstas nesta Lei (BRASIL, 2014). 
Portanto, no contexto brasileiro, a exclusão de dados pessoais torna-se um direito pessoal e submetido aos provedores de aplicações, ressalvadas as exceções legais. Assim, cabe a esses agentes, responsáveis pelos serviços, conteúdos e aplicações disponíveis na rede, a incumbência de abster-se da disponibilização de determinadas informações.

Alves e Gofas (2017) afirmam que o direito ao esquecimento pode ser compreendido como o poder que confere escolha ao indivíduo que, por razões pessoais, não deseja que certos aspectos de sua vida sejam lembrados. Esta faculdade, argumentam, concede autonomia a uma pessoa para pleitear a retirada, do ciberespaço, de todo o teor acerca de si mesmo e que, de alguma forma, Ihe cause sofrimento, constrangimento ou propicie ofensa moral.

Apesar de configurar-se numa proteção importante para os direitos fundamentais da pessoa humana, o risco representado pelo exercício amplo e irrestrito do direito ao esquecimento não pode, ainda, ser mensurado. É pacífico que a internet, a serviço da sociedade que Baunam (2013) classificou como "confessional", tem um relevante papel na preservação da memória individual e coletiva. Desta forma, além da colisão com outros direitos, o esquecimento digital pode opor-se também à preservação da história que hoje está, ao menos em parte, sendo registrada e armazenada por provedores de serviços, conteúdos, aplicações e nas inúmeras plataformas das redes sociais. Nesse cenário, a então sarcástica observação de Peter Fleischer, conselheiro da Google para temas relativos a privacidade, em discurso proferido durante uma conferência realizada na Europa no ano de 2009, classificando-nos como a sociedade do Alzheimer, pode revelar-se em um vaticínio carregado de precisão (RODRIGUES, OLIVEIRA, 2015).

Ao abordar o direito ao esquecimento no mundo virtual, Rodrigues e Oliveira (2015) destacam uma virada paradigmática em curso. Há pouco tempo, o principal temor no mundo digital era com a possível perda da memória registrada e eventual perda irreversível de informações. Na atualidade, o que assombra a todos é a obsolescência dos meios técnicos de reprodução e transmissão de informações, ou seja, o risco de que nossas informações não sejam conservadas e preservadas. Nos termos de Merzeau (2012, 2013), com 
a emergência do ambiente digital, a contradição entre excesso e falta de informação é radicalizada. Na verdade, argumenta a autora, essa contradição é invertida, uma vez que, antes reclamava-se pelo dever de memória e, atualmente, reivindica-se o direito ao esquecimento.

Rodrigues e Oliveira (2015) destacam, ainda, a inescapável dimensão dialética entre memória e esquecimento. Nas operações de registros de informações em diferentes instituições de memória (arquivos, bibliotecas e museus), tão caras ao campo da Ciência da Informação, reside o binômio lembrar e esquecer. A seleção do que será armazenado ou do que será disponibilizado para acesso público implica na condenação ao esquecimento do restante do acervo informacional. Assim, memória e esquecimento tornamse instrumentos de poder, não só em governos autoritários, mas também em governos democráticos. As decisões sobre o que será "apagado" e o que será conservado surgem a partir de confrontos de interesses antagônicos, conforme destaca Santos (2013).

Lima (2013, p. 281) assevera que a retirada de dados da rede não representa, necessariamente, o ocultamento da realidade. Os limites do direito ao esquecimento, assegura o autor, "[...] serão impostos por outros direitos caros à sociedade, como direito à informação e à liberdade de expressão, em uma espécie de ponderação sobre o interesse em jogo.". Prossegue o pesquisador argumentando que se trata de uma prerrogativa que pode ser exercida por todo o conjunto da sociedade e que o "[...] respeito à privacidade $\mathrm{e}$ à proteção de dados pessoais devem ser entendidos como cruciais para 0 desenvolvimento e sustentabilidade de uma sociedade democrática, bem como ao exercício de outros direitos fundamentais".

Não há unanimidade acerca da suficiência do sistema judiciário para a tomada de decisão a respeito das fronteiras do direito ao esquecimento. Ehrahardt Júnior, Nunes e Porto (2017) defendem que, em qualquer vocabulário, existe um antagonismo entre os termos esquecimento e memória. Alertam os autores que quando o indivíduo, isoladamente, exerce o direito ao esquecimento, a sociedade, coletivamente, tem o seu direito de preservação da memória posto à prova. Nesse sentido, vem do campo da história um alerta 
inquietante, conforme destacam Rodrigues e Oliveira (2015): não é possível saber hoje quais serão os arquivos úteis para o historiador do futuro. Estudos sobre a colaboração dos bancos durante a ocupação nazista na Europa, por exemplo, só foram possíveis graças ao acesso a arquivos repletos de nomes. Futuras análises da sociedade do nosso tempo, inclusive de nossos governantes, exigirão pesquisas em registros de redes sociais, a exemplo do Twitter. Diante desse argumento, portanto, o direito ao esquecimento no ambiente virtual revela-se questionável.

Há, ainda, outros aspectos preocupantes, como a possibilidade de perda de registros de informações acerca de autoridades que exercem cargos públicos. Pessoas com tal ocupação, pela própria natureza do tipo de função que exercem, não devem ser alcançadas pelo direito ao esquecimento:

Em face da generalidade e da vagueza com que está sendo concebido, o direito ao esquecimento certamente dará margem a decisões exorbitantes, inibindo os indivíduos e os veículos de comunicação [...] especialmente quando tais acontecimentos estiverem ligados a pessoas que têm maior influência ou poder na sociedade. (EHRAHARDT JÚNIOR, NUNES, PORTO, 2017, p. 76)

Para além da importância histórica e de preservação da memória da sociedade, as informações disponíveis na internet têm valor econômico. Os dados pessoais e informações públicas ou privadas, a respeito das ações dos usuários na rede, são registradas, analisadas, utilizadas com diversas finalidades e transformaram-se em um valioso recurso. Silveira, Alvelino e Souza (2016) alegam que o uso massivo e mercado de dados pessoais se tornou a principal fonte de renda para gigantescas corporações que pertencem à economia informacional. Os autores advertem que o exercício do direito à privacidade poderia atenuar a expansão exagerada desse mercado.

Lott e Cianconi (2018) ainda observam que se, antes, o registro de informações era efetivado "[...] basicamente em meio físico, hoje, a vasta presença de dispositivos óticos, leitores magnéticos e sensores dos mais diversos tipos, permite a conversão de objetos, fatos e eventos, do real para 0 digital, praticamente no momento em que eles ocorrem".

Lima (2013) retrata fato, de 2006, envolvendo uma estudante que 
desejava ser professora universitária, mas teve o certificado negado, pois o seu comportamento foi considerado inadequado para a profissão pretendida. A negativa se baseou, segundo os funcionários da universidade em tela, na divulgação de uma fotografia, publicada na rede social MySpace, na qual, a então aluna se encontrava fantasiada ingerindo álcool e que, à época, pareceu divertida para a postulante. Alves e Gofas (2017, p. 86) asseguram que as facilidades proporcionadas pela internet e pelas redes sociais demandam registros de informações pessoais que podem ser amplificados e difundidos em questão de segundos. A preservação de aspectos referentes à intimidade dos indivíduos "[...] restam cada vez mais prejudicadas, eis que as informações, uma vez publicadas em um determinado site da internet, em poucos minutos são passíveis de disseminação por todo o ambiente virtual".

Santana Júnior, Lima e Nunes (2015) acrescentam que é ingênuo e paradoxal exigir o esquecimento caso o usuário mantenha-se conectado à internet, uma vez que atualmente diferentes serviços e aplicações web compartilham dados dos usuários. Conforme explicam os autores, quando um usuário acessa uma aplicação web qualquer usando a opção "Entrar com o Facebook", ele está empregando uma solução técnica de interoperabilidade designada microformato, que possui um padrão específico chamado hCard. Nesse tipo de acesso, ocorre a transferência (cópia) de dados de uma app para outra e, nesse cenário, solicitar o apagamento de dados pessoais de uma determinada aplicação não elimina os rastros digitais que ela compartilhou com outras aplicações.

\section{METODOLOGIA}

O propósito delineado para a investigação possibilita que a pesquisa qualitativa, de natureza descritiva, se viabilize por meio de levantamentos bibliográficos e documentais. Para melhor concepção do estudo, a pesquisa bibliográfica buscou, inicialmente, mapear os textos acerca dos assuntos presentes ao longo deste artigo.

O levantamento documental, em seu turno, exigiu a criação de um 
protocolo para recuperação dos documentos nas fontes pesquisadas. A busca por decisões do Superior Tribunal de Justiça (STJ) sobre o direito ao esquecimento, que foram tomadas como corpus documental, foi realizada no site do referido órgão do judiciário. Para possibilitar a coleta dos documentos, ou seja, dos julgados, optou-se por pesquisar ações da área cível, considerando a natureza da medida de esquecimento que se relaciona aos direitos de personalidade. A Figura 1 apresenta a interface de pesquisa disponibilizada pelo STJ.

Figura 1 - Interface de pesquisa, por jurisprudência, do Superior Tribunal de

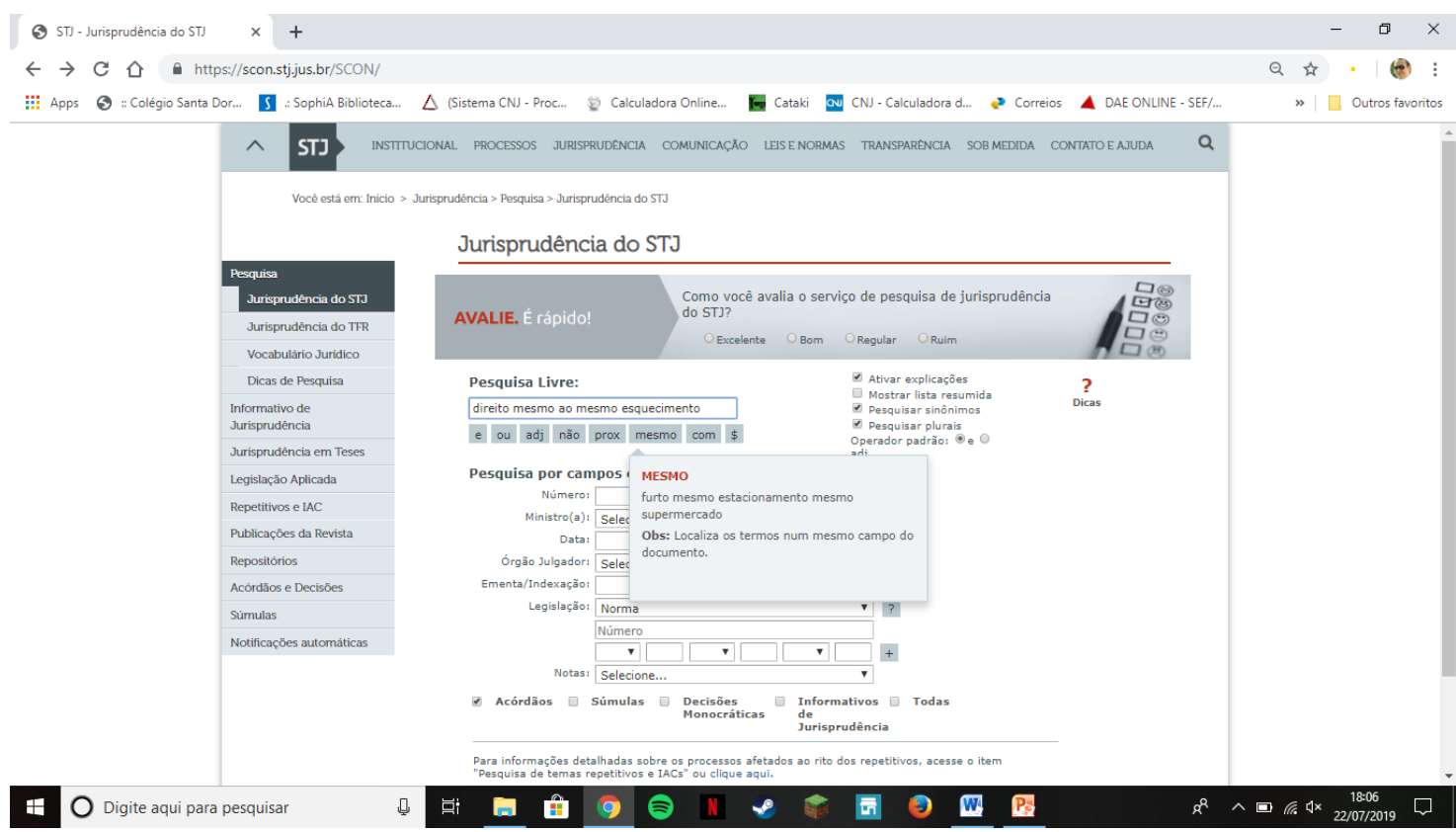

Fonte: Superior Tribunal de Justiça (2019)

Disponível em: https://scon.stj.jus.br/SCON/. Acesso em: 03 de jun. 2019.

Pesquisou-se, assim, as decisões publicadas pelo Superior Tribunal de Justiça, sem delimitação de data ou restrição quanto aos desfechos dos julgamentos, se providos ou não. Os critérios de busca, utilizando-se o recurso de "Pesquisa Livre", abrangeram resultados que contivessem expressões sinônimas e também plurais, mas limitou-se aos acórdãos em virtude desses constituírem decisões finais, coletivas, proferidas por um tribunal superior e que podem ser tomadas como precedentes para situações análogas. Os termos utilizados na pesquisa foram entremeados pelo vocábulo "mesmo" que, na 
lógica do sistema de busca, possibilita a recuperação de documentos que contenham as palavras em qualquer ordem ou distância, desde que estejam dentro de um mesmo campo. Assim, a cadeia de termos construiu-se da seguinte forma: "direito mesmo civil e direito mesmo ao mesmo esquecimento".

A partir da submissão desta estratégia de procura do sistema, obteve-se 15 (quinze) acórdãos. Todavia, após uma breve análise, 09 (nove) processos foram removidos da amostra por se tratar de causas com natureza criminal ou previdenciária, áreas que não estão dentro do espectro desta apuração. São

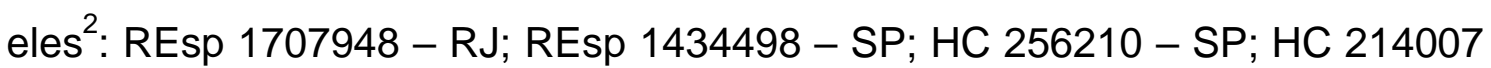
- SP; EREsp 286020 - SC; REsp 225462 - SC; REsp 225269 - SC; REsp 141584 - SC; REsp 142996 - SC. Ao final, 06 (seis) acórdãos foram analisados: REsp 1.631.329 - RJ; REsp 1.660.168 - RJ; REsp 1.369.571 - PE; REsp 1.335.153 - RJ; REsp 1.334.097 - RJ; Aglnt no Resp. 1.593.873 - SP.

Após a obtenção de resultados, apreciou-se integralmente os textos presentes nas petições iniciais e nos fundamentos legais apresentados pelos demandantes, cujos trechos estavam contidos nos acórdãos examinados. A pesquisa abarcou também as decisões dos julgadores e a síntese deste exame que está presente na seção que se segue.

\section{SÍNTESE DO EXAME DOS ACÓRDÃOS}

Os casos analisados na pesquisa ora relatada apresentam narrativas que convergem na alegação sobre a ocorrência de ofensa à honra e moral por fatos desabonadores, sejam eles verídicos ou fictícios. No quadro específico do processo REsp 1.631.329 - RJ tem-se, na petição inicial, do ano de 2012, que uma reportagem veiculada por emissora de TV comportaria um 'viés especulativo e sensacionalista', trazendo à tona fatos passados, mas em versão 'fantasiosa' e que extrapolaria o direito de informar.

Em diferente cenário, no REsp 1.660.168 - RJ, a autora pleiteia a

\footnotetext{
2 REsp refere-se a "Recurso Especial"; enquanto HC é a sigla empregada para "Habeas Corpus"; AgInt alude a "Agravo Interno"; EREsp sintetiza a expressão "Embargos em Recurso Especial". Após o acrônimo e o número do processo, a codificação é composta pela cifra que abrevia o nome do Estado, na Federação, local onde a ação foi impetrada.
} 
desindexação de resultados, nos provedores de busca que estivessem vinculados às suspeitas de que a mesma houvera cometido fraudes em determinado concurso público. Desta forma, a requerente buscava evitar a ocorrência de danos a sua dignidade e privacidade.

Outra narrativa interessante é a que consta no REsp 1.369.571 - PE que trata do pedido de indenização decorrente da publicação de texto em jornal, do ano de 1995, que supostamente imputa, ao titular da ação, a autoria de atentado ocorrido no ano de 1966.

Já no REsp 1.335.153 - RJ é possível aferir o desejo dos autores de garantir o direito ao esquecimento e impedir que fosse revivida, por programa televisivo, a dor experimentada décadas antes em virtude da trágica morte de um ente querido. Este processo se assemelha ao descrito no REsp 1.334.097 - RJ no qual consta o pedido de esquecimento de um indivíduo que fora indiciado como o autor de uma "chacina" ocorrida na década de 1990 no Rio de Janeiro. O requerente foi absolvido da denúncia e, fundamentado também neste argumento, intentou a ação. Em suas narrativas, o outrora investigado por ocasião do massacre, informou que seu nome foi vinculado a cobertura televisiva no ano de 2006, "reacendendo na comunidade onde reside a imagem de chacinador e o ódio social, ferindo, assim, seu direito à paz, anonimato e privacidade pessoal, com prejuízos diretos também a seus familiares" (REsp 1.334.097 - RJ, p. 6). O peticionário alegou também que a divulgação trouxe prejuízos a sua vida profissional e até o levou a abandonar a comunidade onde residia para evitar que "justiceiros" ou traficantes atentassem contra ele e seus familiares.

O AgInt no REsp. 1.593.873 - SP traz, em seu turno, a pretensão de bloqueio definitivo, em mecanismos de busca, de indexações que pudessem, por meio do nome da demandante, conduzir o internauta até páginas que reproduzissem imagens de sua nudez.

Por meio da pesquisa realizada, nota-se que nem todos os pedidos encontram provimento amplo e irrestrito na Justiça. O Superior Tribunal de Justiça não considerou como legítima, por exemplo, a intenção do sujeito de apagar fatos ou reescrever sua própria história. Isto é explicitado no processo REsp 1.660.168 - RJ, no qual o Tribunal apenas assegura a possibilidade de 
discutir a forma como as informações vêm sendo utilizadas e para quais fins. Neste sentido, o REsp 1.660.168 - RJ apresenta o entendimento que o direito ao esquecimento deve ser utilizado quando não acarrete prejuízo à liberdade de expressão, à memória histórica e ao direito de informar.

Ao considerar que são estreitos os limites entre 0 direito ao esquecimento e o direito à informação, no REsp 1.631.329 - RJ os julgadores desse litígio destacam que, para ser esquecido e não prejudicar o que se busca informar, é preciso que haja uso degradante ou desrespeitoso da imagem ou que ela seja objeto de exploração comercial.

Nota-se que o REsp 1.631.329 - RJ traz uma importante análise sobre o direito a memória:

Todo ato que implica restrição à informação de um dado histórico deve ser avaliado dentro do que se compreende como relevante do ponto de vista da memória social. Naturalmente, isso não implica uma supervalorização de toda e qualquer informação, tão somente por sua articulação com um dado histórico. Ao contrário disso, "memória" não é apenas manter impressões, mas também organizar o acesso aos dados. Essa atividade combina lembrar e esquecer (p. 31-32).

E, ainda, conclui:

Eventual abuso na transmissão do fato, cometido, entre outras formas, por meio de um desvirtuado destaque da intimidade da vítima ou do agressor, deve ser objeto de controle sancionador. A razão jurídica que atribui ao portador da informação uma sanção, entretanto, está vinculada ao abuso do direito e não à reinstituição do fato histórico, afinal, o exercício regular do direito, não pode se subverter, ele mesmo, em uma transgressão à lei, na modalidade abuso do direito, desvirtuando um interesse aparentemente legítimo, pelo excesso (RESP 1.631.329, p. 33).

Os documentos analisados REsp 1.334.097 - RJ, REsp 1.369.571 - PE e REsp 1.335.153 - RJ apontam como conflitantes a liberdade de expressão e o direito à informação em oposição à privacidade, intimidade e a honra, proclamados no art. 5o, incisos IV, V, IX, X e XIV, arts. 220 e 221, da Constituição Federal de 1988. Também mencionam que o Superior Tribunal de Justiça tem entendido que o direito à informação não é absoluto, uma vez que encontra limites na legislação, em especial nas garantias constitucionais relativas à dignidade da pessoa humana, como citado no REsp 1.369.571 - PE:

Orientação jurisprudencial do Superior Tribunal de Justiça 
firmou-se no sentido de que os direitos à informação e à livre manifestação do pensamento não possuem caráter absoluto, encontrando limites na legislação infraconstitucional e nas garantias constitucionais essenciais à concretização da dignidade da pessoa humana (REsp 1.369.571 - PE, p. 27).

Constata-se que, conforme proferido no caso do REsp 1.335.153 - RJ, o direito ao esquecimento deve ser ponderado em função da historicidade do fato, ou seja, dada a sua grande repercussão. Coerentemente, no REsp 1.369.571 - PE consignou-se que o desejado fato a ser esquecido faz parte da história do país, não se tratando de um acontecimento qualquer, mas algo que integra a memória brasileira e pode servir de fonte de informação inclusive para as pesquisas científicas. Ressaltou-se, no mesmo processo, que a liberdade de informação não pode ser desvirtuada ao se praticar atos que possam causar danos à imagem do indivíduo, cabendo a quem o faz, isto é, a quem divulga a informação, a responsabilidade de manter o compromisso ético com a veracidade dos fatos, bem como não assumir uma posição de caráter malicioso, injurioso ou difamatório:

A Ré cumpriu com sua função social de informar, alertar e abrir o debate sobre o controvertido caso. Os meios de comunicação também têm este dever, que se sobrepõe ao interesse individual de alguns, que querem e desejam esquecer 0 passado. O esquecimento não é o caminho salvador para tudo. Muitas vezes é necessário reviver o passado para que as novas gerações fiquem alertas e repensem alguns procedimentos de conduta do presente (RESP 1.369.571 - PE, p. 5).

A pesquisa realizada revelou também que o direito ao esquecimento propicia uma complexidade que transcende as fronteiras da legislação e das doutrinas na área do Direito. Os magistrados, então, recorrem aos autores e pesquisadores, antes pouco frequentes, nas decisões dos tribunais e reconhecem a emergência de novos direitos ou reinterpretações de direitos antes considerados consagrados. Os acórdãos, por exemplo, REsp 1.334.097 - RJ e REsp 1.335.153 - RJ citam trechos de Bauman (2013):

Um dos danos colaterais da "modernidade líquida" tem sido a progressiva eliminação da "divisão, antes sacrossanta, entre as esferas do 'privado' e do 'público' no que se refere à vida humana", de modo que, na atual sociedade da hiperinformação, parecem evidentes os "riscos terminais à privacidade e à autonomia individual, emanados da ampla 
abertura da arena pública aos interesses privados [e também o inverso], e sua gradual, mas incessante transformação numa espécie de teatro de variedades dedicado à diversão ligeira" (BAUMAN, 2013, p. 111-113). Diante dessas preocupantes constatações, o momento é de novas e necessárias reflexões, das quais podem mesmo advir novos direitos ou novas perspectivas sobre velhos direitos revisitados (REsp 1.334.097 - RJ, p. 2).

Com boa dose de desesperança, Bauman (2013) afirma que um dos danos colaterais dessa modernidade líquida tem sido a progressiva eliminação da divisão, até então sacrossanta, entre as esferas pública e privada da vida humana (corporal e espiritual), tendo nascido uma inédita sociedade confessional. Nos termos do autor, trata-se de uma sociedade confessional na qual os modernos confessionários são dotados de microfones que capturam segredos (antes revelados somente a Deus ou seus mensageiros terrestres) e os transmitem para autofalantes instalados em praças públicas, lugares outrora destinados ao debate de questões urgentes e comunitárias. O pressentimento que Peter Ustinov revelou na década de cinquenta do século $X X$ parece assumir um caráter profético: "Este é um país livre, madame. Nós temos o direito de compartilhar a sua privacidade no espaço público" (REsp 1.335.153 RJ, p. 20, grifos no original).

Observa-se, nos trechos acima, a preocupação do judiciário com o novo modelo informacional da sociedade que traz, em sua esteira, a percepção de que está havendo uma modificação nos valores defendidos por gerações passadas. Vive-se em uma sociedade na qual os espaços virtuais têm sido arena pública de exposição de elementos privados ou íntimos. Defronta-se com uma época em que os vínculos frágeis construídos nas redes sociais acabam por corroer a privacidade, levando as pessoas a uma servidão voluntária em troca da promessa de visibilidade e pertencimento. Esta realidade hodierna criou uma nova mercadoria para o consumo da coletividade, um produto que decorre da e consiste na exposição pessoal, pois ser espionado ou devassado tem o potencial de tornar um sujeito importante e popular, podendo conferir-Ihe, em alguns casos, riqueza e notoriedade.

Como bem observa Paulo José da Costa Júnior, dissertando acerca do direito de ser deixado em paz ou o direito de estar só (the right to be let alone): Aceita-se hoje, com surpreendente 
passividade, que o nosso passado e o nosso presente, os aspectos personalíssimos de nossa vida, até mesmo sejam objeto de investigação e todas as informações arquivadas e livremente comercializadas. $\mathrm{O}$ conceito de vida privada como algo precioso, parece estar sofrendo uma deformação progressiva em muitas camadas da população. Realmente, na moderna sociedade de massas, a existência da intimidade, privatividade, contemplação e interiorização vem sendo posta em xeque, numa escala de assédio crescente, sem que reações proporcionais possam ser notadas. (RESP 1.335.153 $\mathrm{RJ})$

A pesquisa revela, portanto, que as novas dinâmicas sociais que emergem no universo da internet propiciam que sejam revisitadas antigas questões éticas e jurídicas. Nesse contexto, o Poder Judiciário se vê obrigado a enfrentar novamente alguns dilemas que podiam ser tomados como pacificados, ou seja, para os quais já havia relativo consenso no direito brasileiro.

Os casos analisados expõem interpretações acerca da responsabilidade de provedores de pesquisa (motores de busca como, por exemplo, Google) em garantir o sigilo, a segurança e a inviolabilidade dos dados cadastrais de seus usuários e das buscas por eles realizadas. Porém, em REsp. encontra-se o reconhecimento da dificuldade se efetivar na prática esses princípios:

Mesmo com a existência de diversos mecanismos de filtragem do conteúdo da Internet, na maioria das vezes, é inviável ao provedor da busca exercer alguma forma controle sobre os resultados da busca. Isso porque é problemática a definição de critérios que autorizariam o veto ou o descarte de determinada página. (Aglnt no Resp. 1.593.873 - SP, p.16)

$\mathrm{Na}$ mesma decisão, o Superior Tribunal de Justiça manifesta 0 entendimento de que os provedores de pesquisa não devem ser responsabilizados, uma vez que eles:

(i) não respondem pelo conteúdo do resultado das buscas realizadas por seus usuários; (ii) não podem ser obrigados a exercer um controle prévio do conteúdo dos resultados das buscas feitas por cada usuário; e (iii) não podem ser obrigados a eliminar do seu sistema os resultados derivados da busca de determinado termo ou expressão. (AgInt no Resp. 1.593.873 SP, p.16)

Isto posto, compreende o Superior Tribunal de Justiça, apesar de reconhecer-se a iminente necessidade de aprofundamento da discussão sobre o tema, que não se pode atribuir aos provedores de busca a função de censor 
digital, vigiando o que pode ou não ser acessado pelas pessoas.

O acórdão do AgInt no Resp. 1.593.873 - SP apresenta uma interessante síntese do entendimento utilizado até então pelo Superior Tribunal de Justiça:

Por fim, com relação à jurisprudência desta Corte Superior, no que se refere ao direito do esquecimento, há duas situações distintas. A primeira não aborda diretamente a responsabilidade do provedor de aplicação de busca na internet, ao envolver apenas empresas de comunicação televisiva, como nos julgamentos dos REsp 1.335.153/RJ e REsp 1.334.097/RJ. A segunda, em que se encontra o decidido no REsp 1.316.921/RJ, quando aborda a questão do direito ao esquecimento no ambiente digital, rejeita imputar ao provedor de buscas a obrigação de fiscalizar o conteúdo acessível ao público, como expressamente afirmado naquela oportunidade: "Dessa forma, não há fundamento legal que permita impor aos provedores de pesquisa a obrigação de eliminar do seu sistema os resultados que apontem para uma foto ou texto específico, sob a alegação de implementar o direito ao esquecimento de qualquer requerente. (REsp 1.316.921/RJ, Terceira Turma, julgado em 26/06/2012, DJe 29/06/2012. Grifo do autor)." (AgInt no Resp. 1.593.873 - SP, p. 16)

\section{CONSIDERAÇÕES FINAIS}

O objetivo traçado para esta pesquisa, o qual consistiu em analisar o pronunciamento dos tribunais brasileiros no que tange a aplicação do direito ao esquecimento no contexto digital, foi atingido por meio do exame dos acórdãos emanados pelo STJ.

Percebe-se que o direito ao esquecimento vem sendo discutido tanto em razão de veiculação de fatos privados em diversos canais de comunicação, como no caso de registros de antecedentes criminais.

O que se torna nítido, nos acórdãos, é a indispensabilidade de avaliar o caso concreto, considerando todas as suas nuances, para se chegar a uma conclusão acerca da violação ou não do direito de perenizar a informação ou sobre a legitimidade de se permitir esquecê-la. Adicionalmente, conclui-se, dado ao baixo índice de acolhimento das ações dentre os seis acórdãos analisados, que nem todos os pedidos encontram provimento amplo e irrestrito na Justiça. Depreende-se igualmente que os textos legais e doutrinas não têm 
sido suficientes para embasar as decisões dos tribunais, pois autores antes ausentes nas redações de sentenças garantem, atualmente, até mesmo cocitações nas sentenças.

Observou-se ainda que os recursos analisados contêm uma série de divergências entre as câmaras julgadoras e, dentro delas, dos ministros que as compõem. Assim, os acórdãos apresentam decisões finais semelhantes, porém com fundamentos distintos.

Comprova-se também, neste estudo das decisões proferidas pelo STJ, que as pessoas se indignam mais com uso de suas imagens relacionadas às práticas criminosas ou ofensivas à moral ou honra. Mas, há, mesmo que em menor número, causas movidas por indivíduos que desejam o anonimato em função da sua atual condição social ou por questão de segurança, situações em que se pretende deixar no passado ocorrências que não mais condizem com os atuais propósitos de vida.

Além do direito de serem esquecidas, as partes que intentaram as ações analisadas nesta pesquisa pretendiam ser indenizadas em aspectos patrimoniais, alegando ter havido exploração comercial de imagens ou, em certos casos, motivadas por razões de afronta aos direitos de personalidade, como a moral e a honra, garantias asseguradas pela Constituição Federal da República Federativa do Brasil.

Nota-se igualmente que um tema de discussão recorrente nas ações examinadas é o limite entre o direito ao esquecimento e o direito à informação. A partir da análise dos acórdãos é possível concluir que o Superior Tribunal de Justiça considera que o direito ao esquecimento tem sua origem histórica no âmbito das condenações penais, como forma de garantir ao ex-condenado o direito de retorno ao convívio social sem sofrer discriminações.

Por fim, entende-se também que a existência de um diagnóstico, realizado na internet, a respeito da efetividade na execução das sentenças de desindexação ou de remoção do material solicitado pelo requerente, possibilitaria uma conclusão relativa à eficácia das decisões legais. Assim, sugere-se que investigações futuras abordem tais aspectos ou outros que não foram abrangidos pelo conteúdo deste. 


\section{REFERÊNCIAS}

ALVES, F. D.; GOFAS, F. G. O transexual e o direito ao esquecimento no ciberespaço após a mudança de gênero: por um tratamento compatível com o constitucionalismo contemporâneo brasileiro, de promoção aos direitos humanos fundamentais e garantia à diversidade. Revista Publicum, v. 3, n. 1, p. 78-99, 2017. Disponível em: https://www.epublicacoes.uerj.br/index.php/publicum/article/view/25187. Acesso em: 28 jan. 2020.

BARROS, A. J. S.; LEHFELD, N. A. S. Fundamentos de metodologia científica. São Paulo: Pearson, 2007.

BAUMAN, Z. Danos colaterais: desigualdades sociais numa era global. Rio Janeiro: Zahar, 2013.

BRAMAN, S. Change of state: information, policy, and power. Cambridge: MIT Press, 2006. P. 67-78.

BRASIL. Lei $n^{\circ} 12.965$ de 23 de abril de 2014. Estabelece princípios, garantias, direitos e deveres para o uso da internet no Brasil, [2014]. Disponível em: http://www.planalto.gov.br/CCIVIL_03/_Ato2011-2014/2014/Lei/L12965.htm. Acesso em: 28 jan. 2020.

COMERLATO, M. B. (2014). A efetividade do direito ao esquecimento. In: Congresso Brasileiro da Sociedade da Informação, 7., 2014, São Paulo. Anais [...] São Paulo, 2014. Disponível em:

http://www.revistaseletronicas.fmu.br/index.php/CBSI/article/view/537. Acesso em: 28 jan. 2020.

EHRHARDT JÚNIOR, M. A. A.; NUNES, D. R. M.; PORTO, U. C. R. Direito ao esquecimento segundo o STJ e sua incompatibilidade com o sistema constitucional brasileiro. Revista de Informação Legislativa, v. 54, n. 213, p. 6380, 2017. Disponível em:

https://www12.senado.leg.br/ril/edicoes/54/213/ril_v54_n213_p63.pdf. Acesso em: 28 jan. 2020.

ENUNCIADOS aprovados na VI Jornada de Direito Civil. 2013. Disponível em: https://www.cjf.jus.br/enunciados/. Acesso em: 28 jan. 2020.

LIMA, E. N. K. P. Direito ao esquecimento: discussão europeia e sua repercussão no Brasil. Revista de Informação Legislativa, v. 50, n. 199, p. 271283, 2013. Disponível em:

https://www12.senado.leg.br/ril/edicoes/50/199/ril_v50_n199_p271. Acesso em: 28 jan. 2020.

LOTT, Y. M.; CIANCONI, R. B. Vigilância e privacidade do contexto do big data e dados pessoais: análise da produção da Ciência da Informação no Brasil. 
Perspectivas em Ciência da Informação, v. 23, n. 4, p. 117-132, 2018.

Disponível em: http://www.scielo.br/scielo.php?script=sci_abstract\&pid=S141399362018000400117\&lng=en\&nrm=iso\&tlng=pt. Acesso em: 28 jan. 2020.

MERZEAU, L. Faire mémoire de nos traces numériques. E-dossiers de l'audiovisuel, 2012. Disponível em: https://halshs.archives-ouvertes.fr/halshs00727308/document. Acesso em: 17 dez. 2019.

MERZEAU, L. =7Les paradoxes de la mémoire numérique. Intercedi, n. 244, p. 68-71, 2013. Disponível em: http://merzeau.net/wpcontent/uploads/2013/09/InterCDI-Merzeau.pdf. Acesso em: 15 jan. 2020.

RODRIGUES, G.; OLIVEIRA, E. B. Memória e esquecimento no mundo virtual: os mesmos fios tecendo uma nova trama? Liinc em Revista, v. 11, n. 1, p. 91 105, 2015. Disponível em: http://revista.ibict.br/liinc/article/view/3633. Acesso em: 28 jan. 2020.

SANTANA JÚNIOR, C. A.; LIMA, C. O. A.; NUNES, A. M. A. Uma reflexão sobre $o$ direito ao esquecimento e sua relação com as máquinas sociais: 0 direito de desconectar-se. Liinc em Revista, v. 11, n. 1, p. 106-121, 2015. Disponível em: http://revista.ibict.br/liinc/article/view/3624. Acesso em: 28 jan. 2020.

SANTOS, M. S. dos. Memória coletiva e identidade nacional. São Paulo: Annablume, 2013.

SILVEIRA, S. A.; AVELINO, R.; SOUZA, J. A privacidade e o mercado de dados pessoais. Liinc em Revista, v. 12, n. 2, p. 217-230, 2016. Disponível em: http://revista.ibict.br/liinc/article/view/3719. Acesso em: 28 jan. 2020.

\title{
A DIGITAL OBLIVION IN BRAZILIAN COURTS: THE RIGHT TO BE FORGOTTEN ACCORDING TO THE JUDGMENTS OF THE SUPERIOR COURT OF JUSTICE
}

\begin{abstract}
Introduction: The application of the right to oblivion in the digital context by Brazilian courts has proved to be a controversial topic inserted in the list of information policies, especially when the ways of disseminating information about people and information become more frequent, varied and easy. the facts that surround them, creating a fine line between privacy and freedom of expression. Objective: To analyze the pronouncements of the Brazilian courts regarding the application of the right to forgetting in the digital context. Methodology: To achieve this goal, a research was carried out based on bibliographic and documentary surveys, whose methodological path is presented in the third section of this article. Before it, the right to be forgotten on the internet is the subject addressed in the second section of the text. The following is a summary resulting from the examination of the judgments selected for the study and, at the end, the final considerations on the topic under discussion. Results: Among the
\end{abstract}


results achieved, it is proved that, in addition to the right to be forgotten, the parties who initiated the actions intended to be indemnified in equity aspects. It was also noted that a recurring theme in the cases studied is the limit between the right to be forgotten and information. Conclusions: It was found, given the low rate of acceptance of the lawsuits among the analyzed judgments, that not all requests are granted in the Brazilian courts. It was also concluded that the legal texts and doctrines have not been sufficient to support the decisions of the courts, since authors who were absent in the judgments currently guarantee even co-citations in the sentences.

Descriptors: Right to oblivion. Digital oblivion. Brazilian Justice. Superior Court of Justice. Information policy.

\title{
A EL OLVIDO DIGITAL EN LOS TRIBUNALES BRASILEÑOS: EL DERECHO A SER OLVIDADO EN LAS SENTENCIAS DEL TRIBUNAL SUPERIOR DE JUSTICIA
}

\begin{abstract}
RESUMEN
Introducción: La aplicación del derecho al olvido en el contexto digital por parte de los tribunales brasileños ha demostrado ser un tema controvertido insertado en la lista de políticas de información, especialmente cuando las formas de diseminar información sobre personas e información se vuelven más frecuentes, variadas y fáciles. los hechos que los rodean, creando una delgada línea entre la privacidad y la libertad de expresión. Objetivo: analizar los pronunciamientos de los tribunales brasileños sobre la aplicación del derecho al olvido en el contexto digital. Metodología: Para lograr este objetivo, se realizó una investigación basada en encuestas bibliográficas y documentales, cuya ruta metodológica se presenta en la tercera sección de este artículo. Antes de eso, el derecho a ser olvidado en Internet es el tema tratado en la segunda sección del texto. El siguiente es un resumen resultante del examen de los juicios seleccionados para el estudio y, al final, las consideraciones finales sobre el tema en discusión. Resultados: Entre los resultados obtenidos, se demuestra que, además del derecho a ser olvidado, las partes que iniciaron las acciones tenían la intención de ser indemnizados en los aspectos de equidad. También se observó que un tema recurrente en los casos estudiados es el límite entre el derecho al olvido y la información. Conclusiones: se encontró, dada la baja tasa de aceptación de las demandas entre los juicios analizados, que no todas las solicitudes se otorgan en los tribunales brasileños. También se concluyó que los textos legales y las doctrinas no han sido suficientes para respaldar las decisiones de los tribunales, ya que los autores que estuvieron ausentes en las sentencias actualmente garantizan incluso las citaciones en las sentencias.
\end{abstract}

Descriptores: Derecho a ser olvidado. Olvido digital. Justicia brasileña. Tribunal Superior de Justicia. Política de información

Recebido em: 01.02.2020

Aceito em: 05.02.2021 